\title{
PREVENTING SPONTANEOUS COMBUSTION OF COAL FROM DAMAGING ECOLOGICAL ENVIRONMENT BASED ON THERMOGRAVIMETRIC ANALYSIS
}

\author{
GUO, J. ${ }^{1,2}-$ YAN, H. $^{1}-$ LIU, Y. $.^{1,2^{*}}-$ LI, S. S. ${ }^{1}$ \\ ${ }^{I}$ School of Safety Science and Engineering, Xi' an University of Science and Technology \\ $X i$ 'an 710054, China \\ ${ }^{2}$ Key Laboratory of Western Mine and Hazard Prevention, Ministry of Education of China \\ $X i$ 'an 710054, China \\ *Corresponding author \\ e-mail:18120089021@stu.xust.edu.cn \\ (Received $18^{\text {th }}$ Mar 2019; accepted $17^{\text {th }}$ May 2019)
}

\begin{abstract}
As a global disaster, spontaneous combustion of coal leads to a series of problems, like atmospheric pollution and geological damage, which seriously affects the ecological environment. Therefore, protecting the environment through the prevention of the spontaneous combustion of coal is necessary and worthy of further study. The spontaneous combustion of coal could be characterized by thermogravimetric (TG) characteristics. Thus, the TG test was performed to study the characteristics of non-caking coal during spontaneous combustion. The results show that the combustion process of coal mainly includes loss of water and weight, oxidation, thermal decomposition, combustion and burnout. Both heating rate and oxygen concentration can affect the combustion reaction process of coal. Heating rate is positively correlated with the combustion reaction time, characteristic temperature and oxidation reaction rate of coal. The higher the oxygen concentration, the shorter the combustion reaction time, the lower the characteristic temperature, the higher the oxidation reaction rate. The research results can provide certain theoretical basis for preventing coal spontaneous combustion, and be helpful for the protection of atmospheric environment.
\end{abstract}

Keywords: environmental protection, coal fire, disaster prevention, non-caking coal, spontaneous combustion, TG-DSC synchronous analysis

\section{Introduction}

Coal fire disasters spread all over the world. As a global disaster, spontaneous combustion of coal has caused huge environmental pollution and resource loss, seriously threatening the natural environment and safety production of coalmine (Tomescu et al., 2017). As a large coal country, China's coal resources still occupy a major position in the energy industry (Guo et al., 2018; Guo et al., 2019). However, in the process of resource utilization, a series of damages have been caused to the environment, coal fire disasters are often accompanied by secondary disasters, such as induction of gas explosion and dust explosion, and as a result, large amount of poisonous harmful gas and dust is released, causing pollution to atmosphere environment, endangering human health (Toropov et al., 2018; Benmenine and Bentebbiceh, 2018; Habib et al., 2019). Heavy metals produced by combustion will cause pollution to surface water and shallow groundwater, changes water quality and worsens water environment (Wei and Yu, 2017). In addition, coal fire disasters will cause a series of geological effects, leading to changes in geological structure and degradation of surface soil quality (Zeng et al., 2018), and seriously affecting ecological balance. 
By studying the mechanism of spontaneous combustion of coal, a lot of scholars have given a relatively clear explanation of the mechanism of spontaneous combustion of coal (Deng et al., 2016; Wen et al., 2017; Kong et al., 2017; Lu et al., 2018; Wang et al., 2018). Under the condition of high temperature and low oxygen concentration, the coal sample can continue to react and release a lot of heat to maintain the development of the fire area. During the development and evolution of the fire area, the heating rate of coal samples will decrease due to water evaporation and other reasons, but the overall trend is increasing (Jin et al., 2015). Studies have shown that TG and DTG curves of coal combustion reaction under low oxygen concentration are close to the high temperature zone, the ignition temperature is basically unchanged, the burnout temperature increases, and the combustion rate decreases (Wang et al., 2010). Ash, volatiles, moisture and other factors can affect the minimum ignition temperature of coal, and the minimum ignition temperature of coal with different degrees of metamorphism is different (Deng et al., 2014). Yi et al. (2014) compared the combustion characteristics of coal samples under the atmosphere of $\mathrm{O}_{2} / \mathrm{N}_{2}$ and $\mathrm{O}_{2} / \mathrm{CO}_{2}$ by using the TG analysis method, and found that the combustion performance of coal samples under the atmosphere of $\mathrm{O}_{2} / \mathrm{CO}_{2}$ was better. The higher the volatile content of coal, the more obvious the fluctuation of combustion parameters.

Research on the control of coalfire in the coal field and the mine have had a breakthrough, and effectively reduce the environmental pollution caused by spontaneous combustion of coal. However, factors affecting the spontaneous combustion process of coal are very complex, including external factors are and intrinsic factors (Liu et al., 2014). Under the action of different factors, the changing rules of characteristic parameters of the spontaneous combustion of coal appear different. Therefore, there are still many problems to be solved to prevent the spontaneous combustion of coal.

By using TG experiment method, the combustion characteristic of non-caking coal was studied under the conditions of different oxygen concentration and heating rate in this paper, to reveal the influence laws of the above dual factors on spontaneous combustion of coal. This study is helpful to the prevention and control of spontaneous combustion of non-caking coal, and is of great significance to reduce environmental pollution by saving fossil resources.

\section{Materials and Methods}

\section{Selection and preparation of samples}

In the experiments, the non-caking coal was selected from Shigetai Coal Mine. The central part of raw coal was taken out under the condition of nitrogen protection, and crushed to a particle size of 0.09-0.106 $\mathrm{mm}$. Then, sealed and stored.

\section{Experimental facility and principle}

STA 449 F3 synchronous thermal analyser was adopted in the experiment, which mainly consists of sample holder, temperature programmable furnace, water bath and electronic computer.

According to the experimental principle, coal structure and environmental factors can directly impact the combustion process of pulverized coal. The TG-DSC synchronous thermal analysis experiment is to control the temperature and reaction atmosphere 
conditions by computer; as the temperature in the reaction atmosphere increases according to a certain gradient, the mass change of the pulverized coal can be obtained in real time; as the pulverized coal reaches the set temperature, the relationship between pulverized coal quality and temperature is obtained, i.e., the TG curve. The first-order differentiation of the TG curve can obtain the relationship between the change rate of the pulverized coal mass and the temperature, i.e., the DTG curve.

In the experimental method, the tested coal sample was placed on the top of the sample holder through a ceramic crucible, and directly connected to a precision thermobalance. The precision thermo-balance can simultaneously measure the mass change of the sample and finally obtain the TG curve. The sample crucible and the reference crucible were placed on the top of the sample holder separately, and the thermocouple wire connected on both sides of the crucible can measure the temperature signals in real time. Then it was converted into the heat signal by temperature signal synchronization to finally obtain the DSC curve.

\section{Experimental conditions}

The experiments were conducted in the conductions: the STA 449 F3 synchronous thermal analyser used; the coal sample dosage of $10 \mathrm{mg}$; the temperature range between $30-1000^{\circ} \mathrm{C}$; the total gas flow rate controlled by software to $100 \mathrm{ml} / \mathrm{min}$; the heating rates of $5,10,15^{\circ} \mathrm{C} / \mathrm{min}$ respectively; the pulverized coal in the air atmosphere $(21 \%$, $13 \%$, and $5 \%$ oxygen concentration).

\section{Results}

\section{Thermal weight loss characteristics}

\section{TG/DTG curve characteristics}

Figures 1-3 show the TG/DTG curves of non-caking coal powder at different oxygen concentrations and heating rates. It can be seen from Figures 1-3 that the oxidative combustion process of pulverized coal can be divided into five stages, namely, the water and weight loss stage, the weight gain oxidation stage, the thermal decomposition stage, the combustion stage and the burnout stage.

(1) Loss of water and weight stage $\left(30-180^{\circ} \mathrm{C}\right)$

As the temperature rises, in the initial stage of the pulverized coal, the gas trapped in the non-caking coal clearance is driven to escape from the powder. At the same time, the moisture of the powder also begins to evaporate by heat, which in turn leads to an increase in weight loss. In contrast, with the evolution of the combustion oxidation process of pulverized coal, the coal-oxygen combination gradually begins, making the powder quality increase with the decrease of water loss, and offsetting the initial water loss quality of pulverized coal. As the temperature increases continuously, this offsetting effect works more significantly until the pulverized coal quality reaches a minimum for the first time, indicating that the initial weight loss stage is terminated.

(2) Weight gain oxidation stage $\left(180-300^{\circ} \mathrm{C}\right)$

Along with the continuous temperature increase, the active group of the pulverized coal powder released from heat is gradually increased, and then the consumption of oxygen is also increased. Most of the oxygen molecules participate in the coal-oxygen complex reaction (Ma et al., 2014), while those not participating in the oxidation reaction adhere to the surface of the pulverized coal molecules, which restricts the 
smooth release of the gas in the combustion products, and increasing the quality of the pulverized coal in a short time.

(3) Thermal decomposition stage $\left(300-410^{\circ} \mathrm{C}\right)$

At this stage, the quality of pulverized coal is macroscopically expressed as weight loss again. The reactive functional groups in the pulverized coal molecules are released, in which the aromatic ring nucleus and other groups are largely broken. Then, the active structure that has not participated in the oxidation reaction in the previous stage also begins to bind oxygen molecules to produce $\mathrm{CO}, \mathrm{CO}_{2}$, and $\mathrm{H}_{2} \mathrm{O}(\mathrm{g})$ etc. Besides, the pulverized coal itself desorbs due to the temperature increase and produce volatiles, resulting in a more decrease in the quality of the pulverized coal.

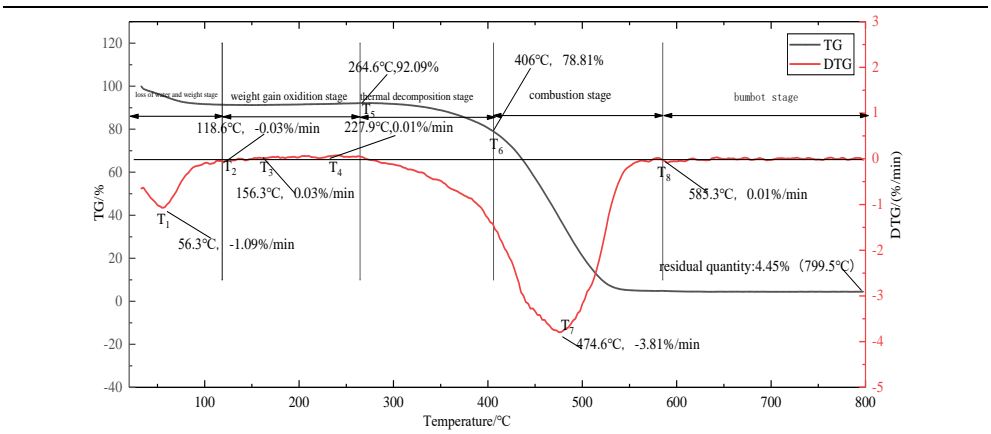

(a) At heating rate of $5^{\circ} \mathrm{C} / \mathrm{min}$

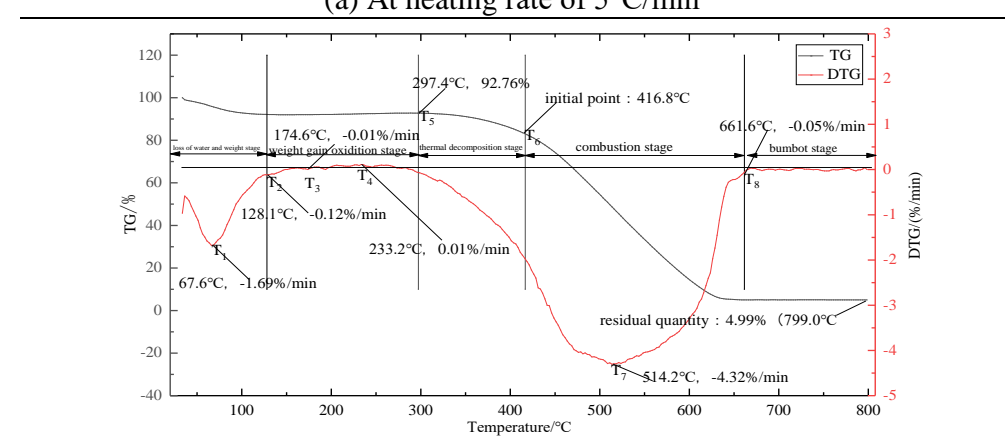

(b) At heating rate of $10^{\circ} \mathrm{C} / \mathrm{min}$

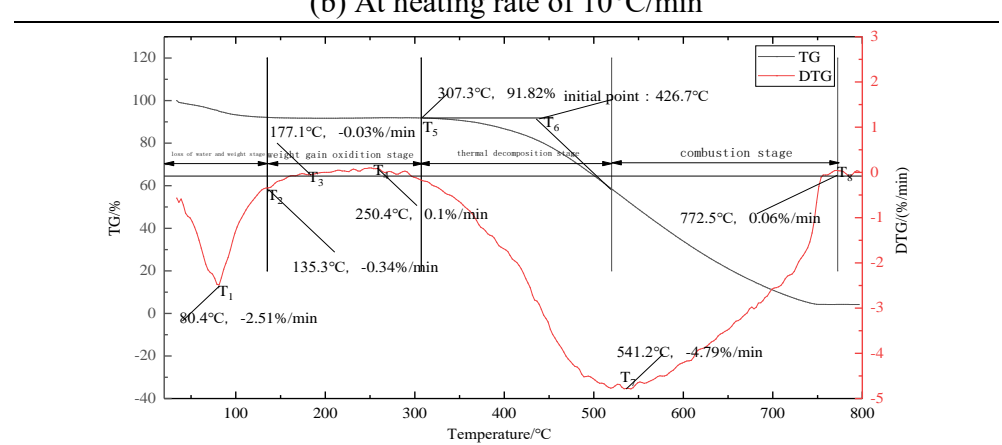

(c) At heating rate of $15^{\circ} \mathrm{C} / \mathrm{min}$

Figure 1. Oxygen concentration of 5\%, TG/DTG curve results at different heating rates

(4) Combustion stage $\left(410-550^{\circ} \mathrm{C}\right)$

When the temperature reaches the ignition temperature, the pulverized coal begins to react, the powder quality decreases rapidly, and a violent combustion reaction occurs 
inside the pulverized coal molecules, which release a large amount of heat, and simultaneously generate many gaseous products such as $\mathrm{CO}, \mathrm{CO}_{2}$, and water vapour, etc. until the combustibles of pulverized coal burn completely and the quality no longer changes.

(5) Burnout stage $\left(550-800^{\circ} \mathrm{C}\right)$

In this stage, the quality of pulverized coal remains basically the same, and the ash content in the pulverized coal directly determines the percentage of the residue remaining after the burnout of pulverized coal.

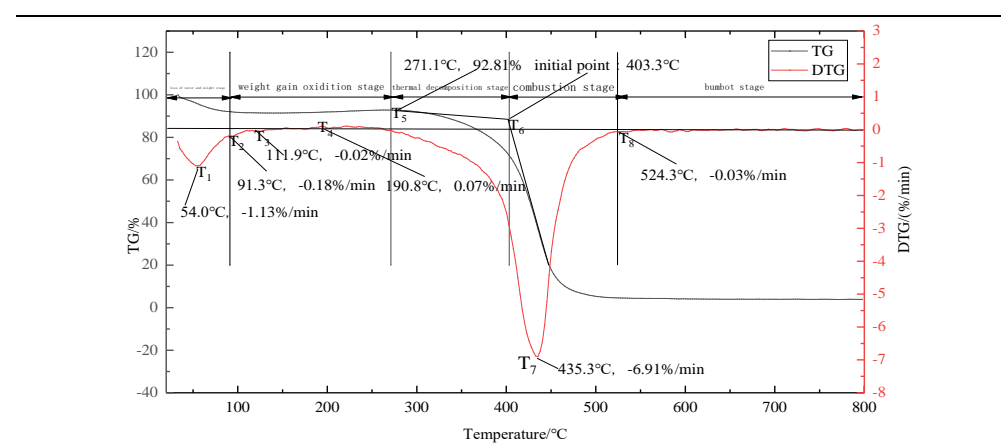

(a) At heating rate of $5^{\circ} \mathrm{C} / \mathrm{min}$

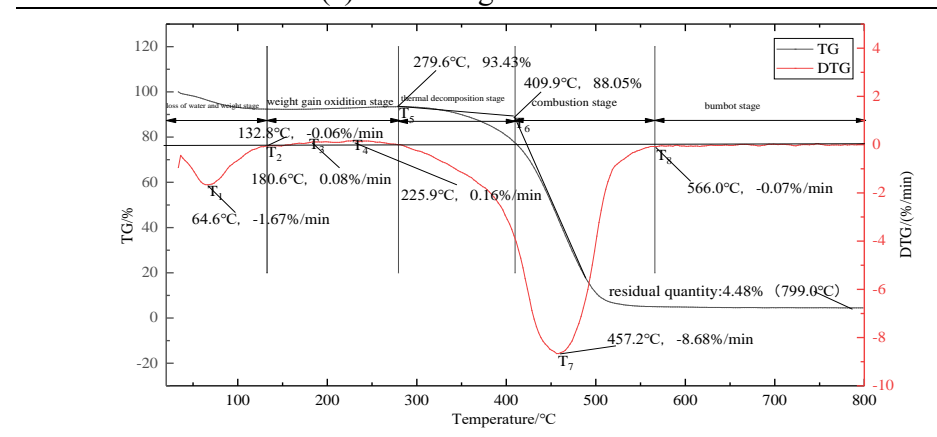

(b) At heating rate of $10^{\circ} \mathrm{C} / \mathrm{min}$

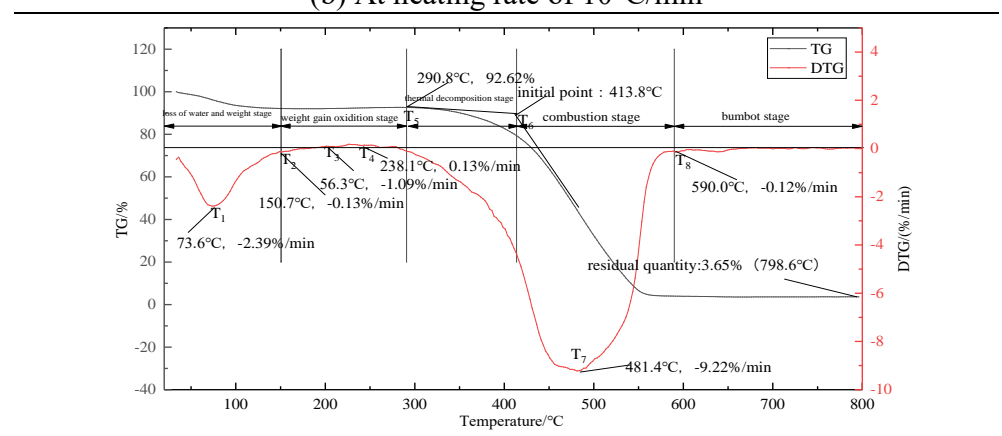

(c) At heating rate of $15^{\circ} \mathrm{C} / \mathrm{min}$

Figure 2. Oxygen concentration of 13\%, TG/DTG curve results at different heating rates

\section{Characteristic temperature}

In the oxidative combustion process of coal sample, the characteristic temperature point of coal can be obtained by analysing the experimental TG data (Zhang et al., 2011), which mainly includes the critical temperature $\left(T_{1}\right)$ with the highest weight loss rate during the early-stage water evaporation and index gas escape, the dry cracking 
temperature at the lowest weight loss point $\left(\mathrm{T}_{2}\right)$, the active temperature of the initial weight gain $\left(\mathrm{T}_{3}\right)$, the increasing temperature $\left(\mathrm{T}_{4}\right)$, the thermal decomposition temperature $\left(T_{5}\right)$ at the maximum quality of coal sample before combustion, the oxygen absorption weight of the coal sample and the ignition temperature $\left(\mathrm{T}_{6}\right)$ at which the reaction consumption reaches equilibrium, the maximum weight loss rate temperature $\left(\mathrm{T}_{7}\right)$ corresponding to the maximum trough of the DTG curve, and the burnout temperature $\left(\mathrm{T}_{8}\right)$ when the pulverized coal is completely burned and the mass is not changed.

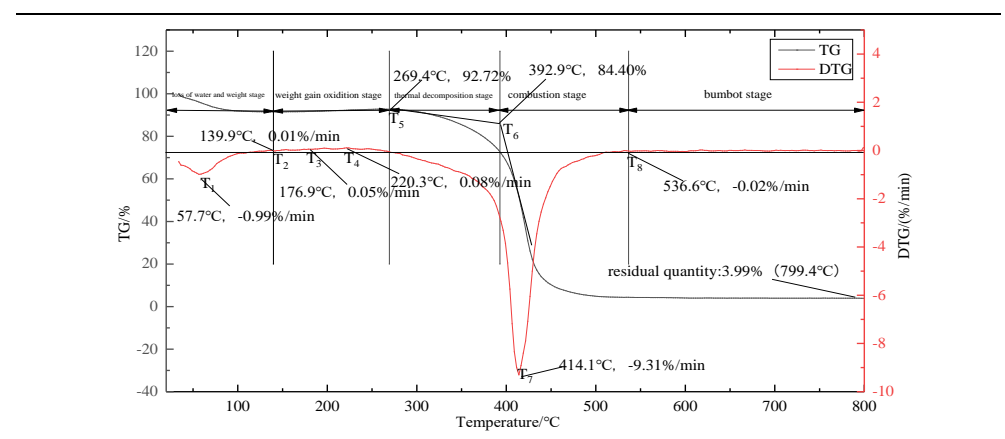

(a) At heating rate of $5^{\circ} \mathrm{C} / \mathrm{min}$

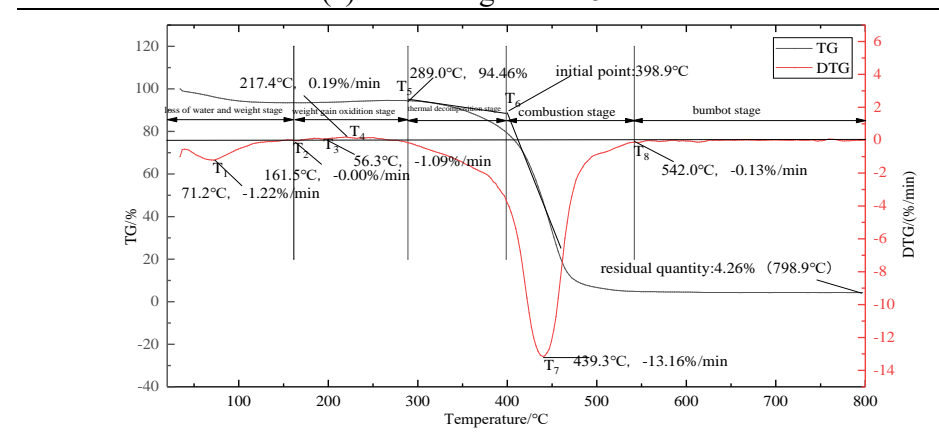

(b) At heating rate of $10^{\circ} \mathrm{C} / \mathrm{min}$

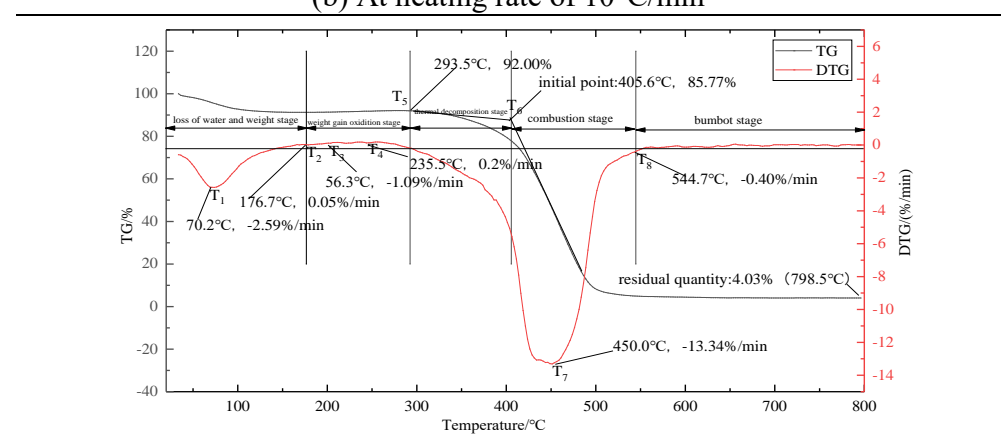

(c) At heating rate of $15^{\circ} \mathrm{C} / \mathrm{min}$

Figure 3. Oxygen concentration of $21 \%$, TG/DTG curve results at different heating rates

\section{Change law of characteristic temperature in combustion process of pulverized coal}

The characteristic temperature during the combustion of pulverized coal is shown in Table 1. In Table 1, the characteristic temperature under different oxygen concentration and different heating rate conditions was compared and analysed. It's found that the characteristic temperature changes significantly from the starting temperature point to 
the ignition temperature range. Therefore, in order to study the combustion process of pulverized coal under the condition of different heating rates and oxygen concentration, the critical temperature $T_{1}$, the dry cracking temperature $T_{2}$, and the ignition temperature $\mathrm{T}_{6}$ were selected. Figure 4 shows the characteristic temperature changes of non-caking coal powder at the same oxygen concentration and different heating rate.

Table 1. Characteristic temperature table of coal sample

\begin{tabular}{c|c|c|c|c|c|c|c|c|c}
\hline $\begin{array}{c}\text { Oxygen } \\
\begin{array}{c}\text { concentration } \\
/ \%\end{array}\end{array}$ & $\begin{array}{c}\text { Heating } \\
\text { rate/ } \\
{ }^{\circ} \mathrm{C} / \mathrm{min}\end{array}$ & $\begin{array}{c}\text { Critical } \\
\text { temperature } \\
\mathrm{T}_{1} /{ }^{\circ} \mathrm{C}\end{array}$ & $\begin{array}{c}\text { Dry } \\
\text { cracking } \\
\text { temperature } \\
\mathrm{T}_{2} /{ }^{\circ} \mathrm{C}\end{array}$ & $\begin{array}{c}\text { Active } \\
\text { temperature } \\
\mathrm{T}_{3} /{ }^{\circ} \mathrm{C}\end{array}$ & $\begin{array}{c}\text { Growth } \\
\text { temperature } \\
\mathrm{T}_{4} /{ }^{\circ} \mathrm{C}\end{array}$ & $\begin{array}{c}\text { Thermal } \\
\text { decomposition } \\
\text { temperature } \\
\mathrm{T}_{5} /{ }^{\circ} \mathrm{C}\end{array}$ & $\begin{array}{c}\text { Ignition } \\
\text { temperature } \\
\mathrm{T}_{6} /{ }^{\circ} \mathrm{C}\end{array}$ & $\begin{array}{c}\text { Maximum } \\
\text { combustion } \\
\text { rate } \\
\text { temperature } \\
\mathrm{T}_{7} /{ }^{\circ} \mathrm{C}\end{array}$ & $\begin{array}{c}\text { Burnout } \\
\text { temperature }\end{array}$ \\
$\mathrm{T}_{8} /{ }^{\circ} \mathrm{C}$
\end{tabular}

Figure 4(a),(b), and (c) depict the changes of characteristic temperature (critical temperature $T_{1}$, dry cracking temperature $T_{2}$, and ignition temperature $T_{6}$ ) at the oxygen concentration of $5 \%, 13 \%$, and $21 \%$ under different heating rates of the non-caking coal.

For non-caking coal, with the oxygen concentration constant, the overall trend of the characteristic temperature for the coal sample increases with the increase of the heating rate. Taking the oxygen concentration of $5 \%$ as an example, for the coal samples at the heating rate of $5^{\circ} \mathrm{C} / \mathrm{min}$, the critical temperature was $56.3^{\circ} \mathrm{C}$, the dry cracking temperature was $118.6^{\circ} \mathrm{C}$, and the ignition temperature was $410.0^{\circ} \mathrm{C}$; at the heating rate of $10^{\circ} \mathrm{C} / \mathrm{min}$, the critical temperature was $67.6^{\circ} \mathrm{C}$, the cracking temperature was $128.1^{\circ} \mathrm{C}$, and the ignition temperature was $416.8^{\circ} \mathrm{C}$; at the heating rate of $15^{\circ} \mathrm{C} / \mathrm{min}$, the critical temperature was increased to $80.4^{\circ} \mathrm{C}$, the dry cracking temperature was $135.3^{\circ} \mathrm{C}$, and the ignition temperature was $426.7^{\circ} \mathrm{C}$.

By comparing (a), (b), and (c) in Figure 4 it can be clearly seen that when the oxygen concentration is constant, the heating rate affects the characteristic temperature during the combustion of the coal sample in different degrees: dry cracking temperature>critical temperature>ignition temperature. The reason may be that the dry cracking temperature is the temperature point at which the weight loss of the coal sample reaches the maximum before combustion; before this temperature point, the coal powder makes the adsorption/desorption and thermal decomposition reaction internally, and these reactions are more affected by the heating rate. Therefore, the heating rate can directly affect the temperature of the cracking temperature. Besides, the heating rate has little effect on the ignition temperature of the coal sample, because a series of reactions by coal ignition shall cause more volatiles and indicator gases from the coal powder., but the heating rate cannot effectively extend the time and progress of these volatiles and gases reacting with oxygen. 


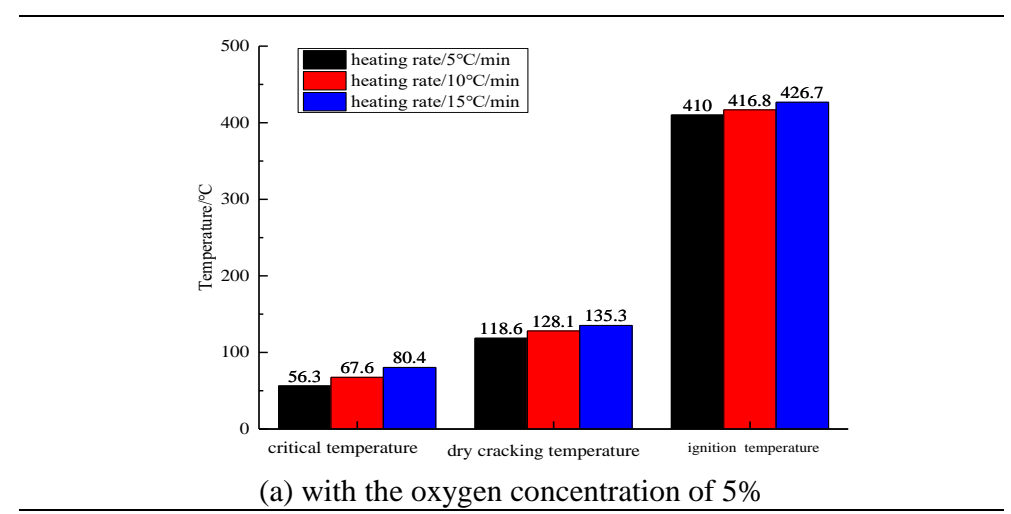

(a) with the oxygen concentration of $5 \%$

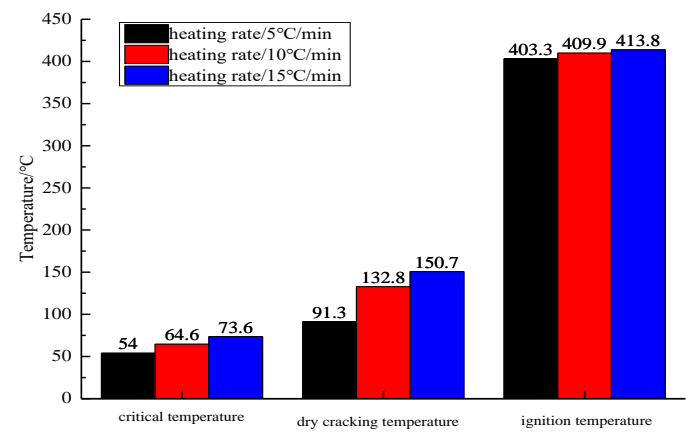

(b) with the oxygen concentration of $13 \%$

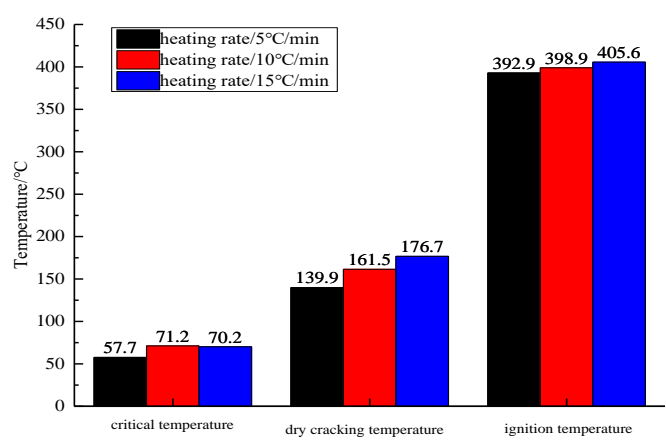

(c) with the oxygen concentration of $21 \%$

Figure 4. Characteristic temperature of non-caking coal at the same oxygen concentration and different heating rate

Figure 5 shows the characteristic temperature changes of non-caking coal powder at the same heating rate and different oxygen concentration. Figure 5(a),(b), and (c) show the characteristic temperatures changes of the non-caking coal powder with different oxygen concentrations at the heating rate of 5,10 , and $15^{\circ} \mathrm{C} / \mathrm{min}$ (critical temperature $\mathrm{T}_{1}$, dry cracking temperature $\mathrm{T}_{2}$, and ignition point $\mathrm{T}_{6}$ ).

Taking the heating rate of $15^{\circ} \mathrm{C} / \mathrm{min}$ as an example, with the oxygen concentration of $5 \%$, the critical temperature of the coal sample was $80.4^{\circ} \mathrm{C}$, the dry cracking temperature was $135.3^{\circ} \mathrm{C}$, and the ignition temperature was $426.7^{\circ} \mathrm{C}$; with the oxygen concentration of $13 \%$, the critical temperature was $73.6^{\circ} \mathrm{C}$, the dry cracking temperature was $150.7^{\circ} \mathrm{C}$, and the ignition temperature was $413.8^{\circ} \mathrm{C}$; with the oxygen concentration of $21 \%$, the critical temperature of the coal sample was reduced to $70.2^{\circ} \mathrm{C}$, the dry cracking temperature was increased to $176.7^{\circ} \mathrm{C}$, and the ignition temperature was lowered to $405.6^{\circ} \mathrm{C}$. 


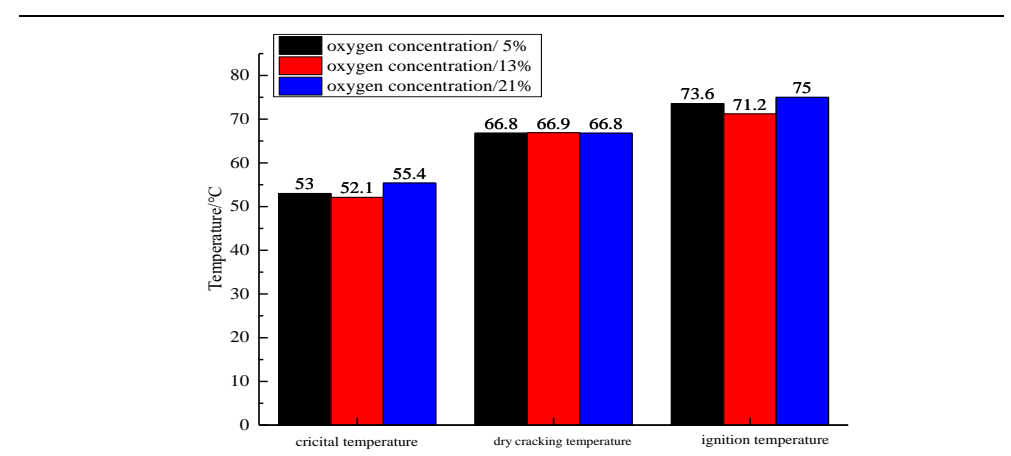

(a) At the heating rate of $5^{\circ} \mathrm{C} / \mathrm{min}$

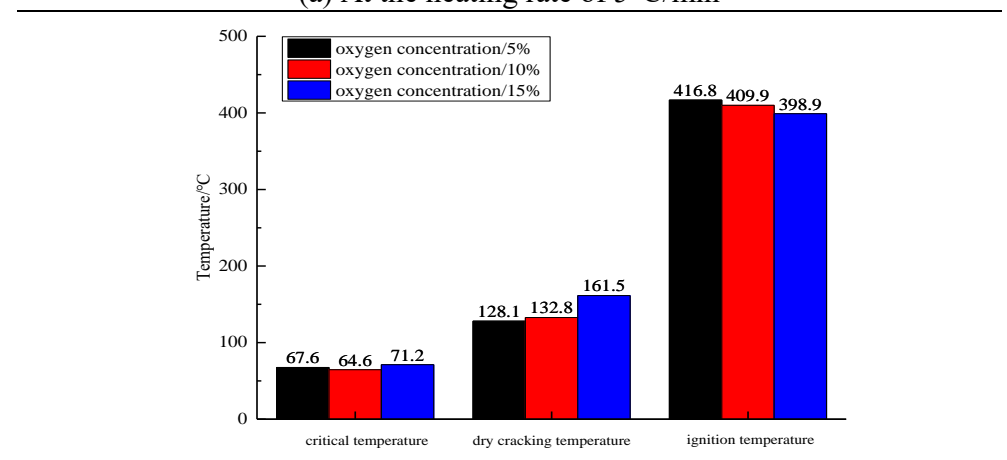

(b) At the heating rate of $10^{\circ} \mathrm{C} / \mathrm{min}$

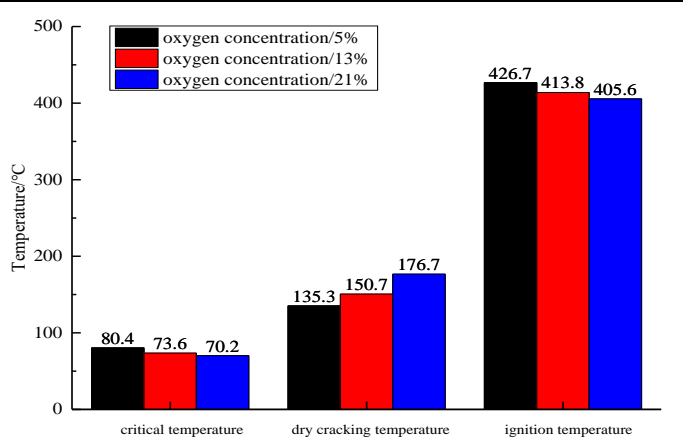

(c) At the heating rate of $15^{\circ} \mathrm{C} / \mathrm{min}$

Figure 5. The characteristic temperature of coal sample in the same heating rate and different oxygen concentration

By comparing $(a),(b)$, and $(c)$ in Figure 5, it can be clearly seen that when the heating rate is constant, the oxygen concentration is positively correlated with the dry cracking temperature of the coal sample combustion process, and negatively correlated with the critical temperature and the ignition temperature (Wang et al., 2014). The effect of oxygen concentration on characteristic temperature is: critical temperature<ignition temperature<dry cracking temperature. During the combustion of coal powder before the critical temperature, less of oxygen is required for the counterreaction is less, so the oxygen concentration has unobvious effects on the change trend of the pulverized coal critical temperature. But the pulverized coal needs to consume a large amount of oxygen for combustion before reaching the ignition temperature, and the oxygen concentration in the environment directly determines the rate of the oxidation reaction, thus, the changes of oxygen concentration have greater effects on the ignition temperature than on heating rate. 


\section{Effect of heating rate and oxygen concentration on combustion process of pulverized coal}

\section{Effect of heating rate on combustion process of pulverized coal}

Under the condition of a certain oxygen concentration, the effect of heating rate on the combustion process of pulverized coal was analysed. Taking the non-caking coal powder under the experimental conditions of $13 \%$ oxygen concentration as an example, the TG, DTG and DSC curves at the heating rates of $5,10,15^{\circ} \mathrm{C} / \mathrm{min}$ were obtained (Figure 6).

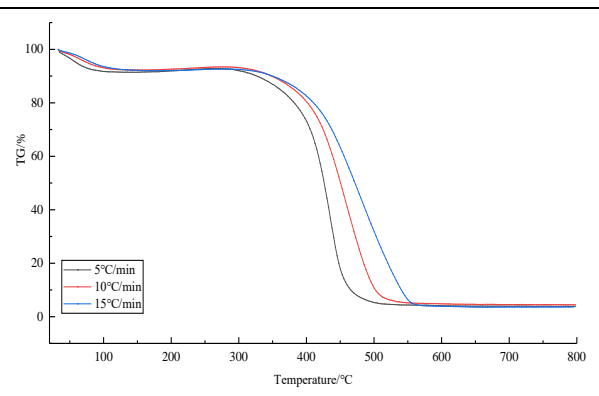

(a)

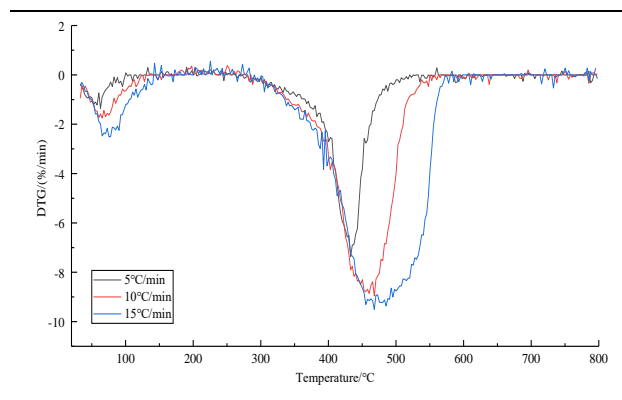

(b)

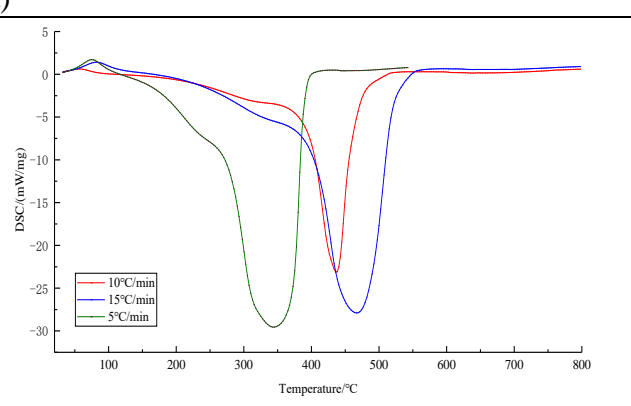

(c)

Figure 6. TG, DTG and DSC curves with oxygen concentration of $13 \%$, heating rate 5, 10 and $15^{\circ} \mathrm{C} / \mathrm{min}$

It can be seen from Figure 6 that under the same oxygen concentration, the heating rate increases continuously, which results in the hysteresis phenomenon of the TG curve. The heating rate can directly determine the temperature of the pulverized coal. However, under the condition of a certain oxygen concentration, the functional groups in the pulverized coal and the structure involved in the pulverized coal combustion reaction cannot all involved in the reaction, and there further occurs the high temperature side shift on the characteristic temperature point of the pulverized coal (Xiao et al., 2007).

It can be seen from the DTG curve that the critical point of the weight loss rate is the ignition point. Before the critical point, the heating rate has little effect on the weight loss rate of coal powder; after the critical point, the effect is more significant. The reason is that the heating rate can prolong or shorten the time of coal and oxygen recombination, and the faster heating rate can cause the non-heterogeneous phase ignition of coal powder, resulting in a longer reaction process. This is expressed as hysteresis in the DTG image. 
The DSC curve shows that the heating rate is positively correlated with the temperature required to reach the maximum exothermic value, which is consistent with the trend of the TG/DTG curve.

\section{Effect of oxygen concentration on combustion process of pulverized coal}

Under the condition of constant heating rate, the effect of oxygen concentration on the combustion process of pulverized coal was analysed. Taking the non-caking coal powder under the experimental conditions of heating rate $10^{\circ} \mathrm{C} / \mathrm{min}$ as an example, the TG, DTG and DSC curves with the oxygen concentration of 5,13 , and $21 \%$ respectively were obtained (Figure 7).

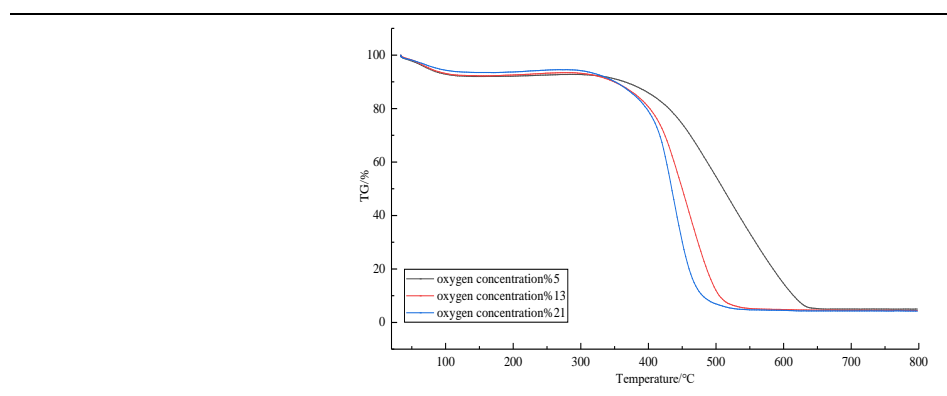

(a)

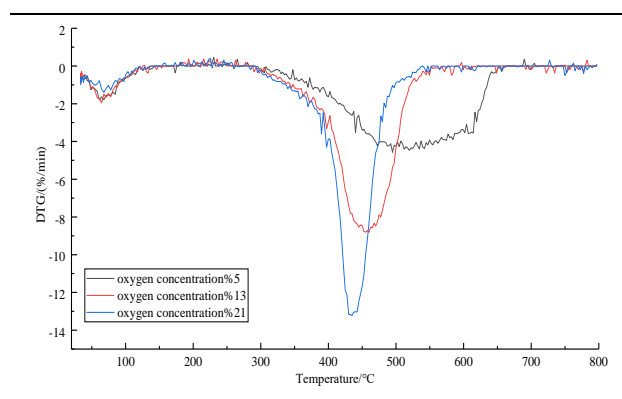

(b)

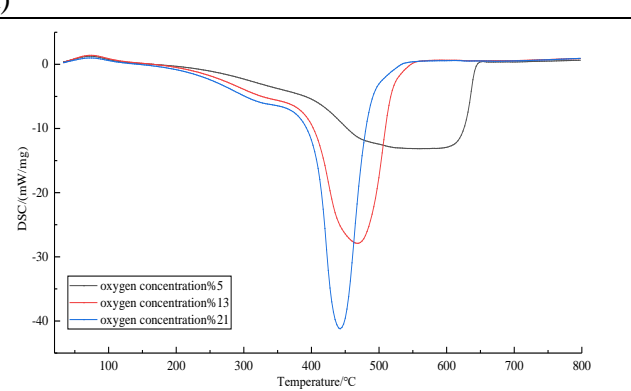

(c)

Figure 7. The results of TG, DTG and DSC curves at the heating rate of $10^{\circ} \mathrm{C} / \mathrm{min}$, oxygen concentration 5,13 , and $21 \%$

It can be seen from Figure 7 that with the heating rate constant, when the oxygen concentration decreases from $21 \%$ to $13 \%$ and then to $5 \%$, TG, DTG and DSC all show a phenomenon of shifting to high temperature. This is because the oxygen concentration can directly determine the amount of oxygen molecules in the oxidation reaction of coal powder. The greater the oxygen concentration, the more oxygen molecular weight involved in the oxygen reaction of coal powder, which shortens the time required to burn coal samples of the same quality, resulting in a lower reaction temperature.

\section{Discussion}

Under the condition of the same oxygen concentration and different heating rate, the characteristic temperature point of non-caking coal samples is shifted to the high temperature point, which is shown as the TG curves will show hysteresis phenomenon with the increase of heating rate. The weight loss rate of coal samples takes the ignition point as the critical point. Before the critical point, the heating rate has little influence on 
the weight loss rate of coal powder, and after the critical point, the effect is significant. In addition, the heating rate has a promoting effect on the weight loss rate of coal samples, and the maximum exothermic strength increases, which shows the same characteristics as the DSC curves. The higher the heating rate is, the longer the reaction process of the coal sample is, indicating that the higher heating rate leads to the heterogeneous combustion of pulverized coal, which to some extent increases the reaction time.

Under certain heating rate, with the reduction of oxygen concentration of coal sample weight loss rate, the maximum heat strength is reduced, this is due to the decreasing concentration of oxygen in oxidation reaction of oxygen reduction, oxidation of coal sample strength decreased. Moreover, the critical point of coal sample weightlessness with low oxygen concentration move to higher temperature, is largely due to reduced oxygen concentration, lead to slow reaction process.

Heating rate and oxygen concentration will affect the combustion reaction of coal samples. When the oxygen concentration is constant, the key to control the ignition of coal is to reduce the heating rate. Similarly, when the heating rate is constant, the key is to reduce the oxygen concentration for inhibit the development of combustion. Based on the TG experiments with different heating rates and oxygen concentrations, the characteristics of combustion of non-caking coal under two-factor conditions were analysed, so as to control the occurrence of coal combustion, and to reduce the waste of resources and the generation of pollutants.

\section{Conclusions}

The combustion process of non-caking coal powder mainly includes the water and weight loss stage of coal, the weight gain oxidation stage, the thermal decomposition stage, the combustion stage and the burnout stage. In the oxidative combustion process of coal samples, the characteristic temperature points of coal samples can be obtained by analysing the TG experimental data, including critical temperature $\left(\mathrm{T}_{1}\right)$, dry cracking temperature $\left(\mathrm{T}_{2}\right)$, active temperature $\left(\mathrm{T}_{3}\right)$, and increasing temperature $\left(\mathrm{T}_{4}\right)$, thermal decomposition temperature $\left(T_{5}\right)$, ignition temperature $\left(T_{6}\right)$, DTG maximum weight loss rate temperature $\left(\mathrm{T}_{7}\right)$, and burnout temperature $\left(\mathrm{T}_{8}\right)$.

The heating rate is positively correlated with the combustion reaction time, characteristic temperature and oxidation reaction rate of pulverized coal. The higher the oxygen concentration, then the shorter the combustion time of the coal sample, the lower its characteristic temperature, and the higher the oxidation reaction rate.

The influence of oxygen concentration on combustion characteristic is more obvious than that of heating rate. Under the condition of high heating rate and oxygen concentration, the maximum exothermic strength of coal sample is the highest, the weight loss is the fastest, and the ignition of the coal is easier.

Due to the diversity of coal types, the TG characteristics of different ranks of coal need to be tested and analysed in future research, so as to reduce resource waste and environmental pollutions, and to prevent spontaneous combustion of coal from damaging ecological environment.

Acknowledgements. This research was supported by the National Key R\&D Program of China (grant number 2018YFC0808201); China Postdoctoral Science Foundation (grant number 2017M623209); Natural Science Basic Research Program of Shaanxi (grant number 2018JQ5080; 2018JM5009); Special scientific research project of Shaanxi Provincial Education Department (grant number 17JK0495). 


\section{REFERENCES}

[1] Benmenine, D., Bentebbiceh, A. (2018): Influence of air preheat temperature and excess air in a reverse flow combustor. - Instrumentation Mesure Métrologie 17(1): 93-111.

[2] Deng, J., Qu, J., Wang, Q. H. (2014): Experimental study on minimum ignition temperature of bituminous coal dust cloud. - Mining Safety and Environmental Protection 41(6): 13-18.

[3] Deng, J., Zhao, J. Y., Zhang, Y. N., Wang, C. P. (2016): Micro-characteristics of spontaneous combustion of second oxidation with different rank coals. - Journal of China Coal Society 41(5): 1164-1172.

[4] Guo, J., Liu, Y., Cheng, X. J., Yan, H., Xu, Y. Q. (2018): A novel prediction model for the degree of rescue safety in mine thermal dynamic disasters based on fuzzy analytical hierarchy process and extreme learning machine. - International Journal of Heat and Technology 36(4): 1336-1342.

[5] Guo, J., Wen, H., Zheng, X. Z., Liu, Y., Cheng, X. J. (2019): A method for evaluating the spontaneous combustion of coal by monitoring various gases. - Process Safety and Environmental Protection 126: 223-231.

[6] Habib, M. A., Basuki, T., Miyashita, S. (2019): Assessment of natural radioactivity in coals and coal combustion residues from a coal-based thermoelectric plant in Bangladesh: implications for radiological health hazards. - Environmental Monitoring and Assessment 191(1): 27.

[7] Jin, Y. F., Guo, J., Wen, H. (2015): Experimental study on combustion characteristic parameters of high temperature and poor oxygen oxide in coal spontaneous combustion. Journal of China Coal Society 40(3): 596-602.

[8] Kong, B., Li, Z. H., Yang, Y. L. (2017): A review on the mechanism, risk evaluation, and prevention of coal spontaneous combustion in China. - Environmental Science and Pollution Research 24(30): 23453-23470.

[9] Liu, W., Qin, Y. P.,Yang, X. B. (2014): Experimental study for impact of volatile matter on spontaneous combustion characteristics of coal. - Journal of China Coal Society 39(5): 891-896.

[10] Lu, X. X., Zhao, H. R., Zhu, H. Q., Han, Y., Xue, X. (2018): Characteristic rule of spontaneous combustion tendency of oxidized coal at recrudescence stage. - Journal of China Coal Society 43(10): 2809-2816.

[11] Ma, L., Deng, J., Wang, W. F. (2014): Effect of $\mathrm{CO}_{2}$ on low temperature oxidation reaction process of coal. - Journal of Xi' an University of Science and Technology 34(4): 379-383.

[12] Tomescu, C., Prodan, M., Vatavu, N. (2017): Monitoring the work environment using thermal imaging cameras in order to prevent the self-ignition of coal. - Environmental Engineering and Management Journal 16(6): 1389-1393.

[13] Toropov, E. V., Osintsev, K. V., Aliukov, S. V. (2018): Analysis of the calculated and experimental dependencies of the combustion of coal dust on the basis of a new methodological base of theoretical studies of heat exchange processes. - International Journal of Heat and Technology 36(4): 1240-1248.

[14] Wang, C. A., Liu, Y. H., Che, D. F. (2010): Experimental investigation on combustion characteristics of coals in low oxygen concentration with thermogravimetry. - Journal of Engineering Thermorphysics 31(10): 1785-1788.

[15] Wang, F. S., Yang, S. Q., Li, Z. B. (2014): Study on heating rate law of low temperature oxidation process of coal samples with different particle sizes. - Coal Science and Technology (5): 62-64.

[16] Wang, K., Zhai, X. W., Deng, J., Liu, X. R., Zhang, Y. N. (2018): Application of liquid $\mathrm{CO}_{2}$ conveying technology for fire control in goaf. - International Journal of Heat and Technology 36(2): 657-662. 
[17] Wei, B., Yu, J. (2017): An investigation of the health effects caused by exposure to arsenic from drinking water and coal combustion: arsenic exposure and metabolism. Environ Sci Pollut Res Int 24(6): 1-8.

[18] Wen, H., Guo, J., Jin, Y. F., Wang, K., Zhang, Y. T., Zheng, X. Z. (2017): Experimental study on the influence of different oxygen concentrations on coal spontaneous combustion characteristic parameters. - International Journal of Oil, Gas and Coal Technology 16(2): 187-202.

[19] Xiao, Y., Ma, L., Wang, Z. P. (2007): Study the characteristic temperature of coal spontaneous combustion process by thermogravimetric analysis. - Coal Science and Technology 35(5): 73-76.

[20] Yi, B. J., Zhang, L. Q., Mao, Z. H. (2014): Effect of the particle size on combustion characteristics of pulverized coal in an $\mathrm{O}_{2} / \mathrm{CO}_{2}$ atmosphere. - Fuel Process Technology 128(10): 17-27.

[21] Zeng, Q., Zhao, L. H. (2018): Investigation of the potential risk of coal fire to local environment: A case study of Daquanhu coal fire, Xinjiang region. - China Science of the Total Environment 640-641: 1478-1488.

[22] Zhang, Y. N., Deng, J., Wen, H. (2011): TG/DTG experiment on characteristic temperature of spontaneous combustion of huating coal. - Journal of Xi'an University of Science and Technology 31(6): 659-662,667. 